\title{
The Effect of Brand Heritage on Brand Trust, Brand Equity, and Brand Perceived Innovativeness: An Exploratory Research (An Abstract)
}

\author{
Anthony Moussa and Virginie de Barnier
}

\begin{abstract}
This research follows two objectives. The first one is to confirm the previously explored relationship between brand heritage, brand trust, and brand equity (Wiedmann et al. 2011). The direct effects of brand heritage on brand equity and brand trust are studied as well as the mediation effect of brand trust in the relationship. The second objective is to explore the brand heritage effect on brand perceived innovativeness, an effect that can be viewed as paradoxical. A quantitative exploratory study is conducted with 137 participants. SEM models are constructed to corroborate five hypotheses. Results indicate that brand trust totally mediates the relationship between brand heritage and brand equity. This confirms Wiedmann et al.'s (2011) results and enhances their generalizability. In addition, results demonstrate a positive significant relationship between brand heritage and brand perceived innovativeness.
\end{abstract}

References Available Upon Request

\footnotetext{
A. Moussa $(\bowtie) \cdot$ V. de Barnier

CERGAM EA 4225, Aix-Marseille Graduate School of Management-IAE, Aix-Marseille

University, Aix-en-Provence, France

e-mail: Anthony.moussa@iae-aix.com; Virginie.de-barnier@iae-aix.com
} 